\title{
POTENCIAL ANTIMICROBIANO DE ÓLEOS ESSENCIAIS ENCAPSULADOS EM LIPOSSOMAS
}

\section{POTENCIAL ANTIMICROBIANO DE ACEITES ESENCIALES ENCAPSULADOS EN LIPOSOMAS}

\section{ANTIMICROBIAL POTENTIAL OF ESSENTIAL OILS ENCAPSULATED INTO LIPOSOMES}

\begin{abstract}
Jaqueline Barbosa de Souza'; Maria Anndressa Alves Agreles²; Davi de Lacerda Coriolano ${ }^{3}$; Sandrelli Meridiana de Fátima Ramos do Santos Medeiros ${ }^{4}$; Isabella Macário Ferro Cavalcanti ${ }^{5}$
\end{abstract}

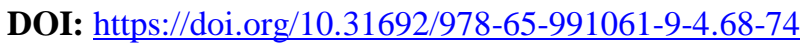

\section{INTRODUÇÃO}

Com o fenômeno da resistência bacteriana associada à pouca descoberta e desenvolvimento de fármacos com atividade antibacteriana frente a cepas resistentes devido a uso excessivo ou insuficiente de antibióticos, a busca por novos tratamentos com maior índice terapêutico têm encontrado espaço nos estudos relacionados a utilização de óleos essenciais como possíveis moléculas bioativas com potencial terapêutica (Miranda et al., 2016). Algumas plantas têm a capacidade de inibir crescimento microbiano mediante a produção de compostos oleosos. Essa capacidade relaciona-se com a composição química dessas substâncias oleosas, que são constituídas principalmente de terpenóides, aldeídos, álcoois, ésteres, fenóis, éteres, cetonas e derivados do oxigênio (Ibrahim et al., 2017).

Óleos essenciais (OE) são produtos odoríferos e constituem-se como elementos voláteis, oriundos do metabolismo secundário das plantas. Têm sido amplamente utilizados na medicina popular para fins antimicrobianos, onde esta capacidade é atribuída, principalmente, aos terpenos e seus derivados (carvacrol, timol, eugenol, terpineno, linalol e carvona). Essas moléculas são capazes de atuarem na funcionalidade da célula bacteriana, principalmente na inibição da síntese de ácidos nucléicos e no metabolismo energético, podendo ser bactericidas ou bacteriostáticos e possuindo espectro de ação tanto frente a bactérias gram positivas, quanto gram negativas (Coimbra et al., 2011; Haiying et al., 2016).

Reações oxidativas, frequentemente presentes em OE, podem formar compostos alergenos e ocasionar redução da atividade biológica. Além disso, os OE podem apresentar baixa solubilidade em meio aquoso, limitando ainda mais suas aplicações farmacêuticas.

\footnotetext{
${ }^{1}$ Bacharelado em Farmácia, Centro Universitário UniSãoMiguel, jaquelinebarbosadesouza@ outlook.com

${ }^{2}$ Bacharelado em Biomedicina, Universidade Federal de Pernambuco, anndressa.agreles@ufpe.br

${ }^{3}$ Bacharelado em Biomedicina, Universidade Federal de Pernambuco, davilacerdas2@ hotmail.com

${ }^{4}$ Doutoranda em Biologia aplicada à saúde, Universidade Federal de Pernambuco, sandrellimeridiana@gmail.com

${ }^{5}$ Professora, Doutora, Universidade Federal de Pernambuco, bel_macario@yahoo.com.br
} 
Visando ultrapassar as limitações de biodisponibilidade, volatilidade e instabilidade química dos $\mathrm{OE}$, foram desenvolvidas estratégias de encapsulação em sistemas de liberação controlada (SLCs). Existem diversos tipos de SLCs, dentre eles, lipossomas, nanopartículas, micelas e micropartículas. Os lipossomas são vesículas esféricas, capazes de encapsular substâncias hidrofílicas e hidrofóbicas, e dessa forma também podem veicular ativos oriundos de fontes naturais, alterando, assim, as propriedades físico-químicas destes, possibilitando um aumento da atividade biológica (Risaliti et al., 2019). Assim, este estudo teve como objetivo realizar uma revisão da literatura sobre como a utilização de OEs encapsulados em lipossomas pode otimizar a atividade antimicrobiana destes compostos.

\section{FUNDAMENTAÇÃO TEÓRICA}

\section{Óleos essenciais (OEs)}

OEs são compostos naturais, voláteis e complexos, produzidos como metabólitos secundários a fim de proteger as plantas de ataques de predadores, parasitas e estresses ambientais (Rai et al., 2017). Sua síntese pode ocorrer em estruturas como botões, flores, folhas, caules, frutas, raízes, e são armazenados, principalmente em células secretoras, células epidérmicas ou tricomas glandulares. Os Oes podem ser constituídos, basicamente, por terpenos, incluindo os mono-, sesqui- e diterpenos (Sherry et al., 2013).

Por possuírem amplo espectro de ações, são relatadas na literatura atividades antifúngica, antioxidante, antiparasitária, e bactericida, que justificam sua aplicação na indústria farmacêutica (Esmaeili et al., 2012; Cui et al., 2015). Entretanto, os OEs apresentam instabilidade nos grupos funcionais, onde o oxigênio age como agente oxidante de álcoois e aldeídos, a luz altera os hidrocarbonetos não saturados e a água causa hidrólise do grupamento éster, levando à perda de sua propriedade terapêutica. Além disso, os OEs apresentam pouca solubilidade em componentes aquosos, portanto, encapsular esses ativos é uma das estratégias necessárias para aumentar a solubilidade, biodisponibilidade, assim como para a proteção e promoção da sua liberação controlada, melhorando, portanto, sua eficácia (Coimbra et al., 2011).

\section{Nanotecnologia e Lipossomas}

A nanotecnologia pode ser definida como o desenvolvimento e caracterização de dispositivos, materiais e sistemas que podem ser manipulados na escala nanométrica. Dentro da nanotecnologia uma área que se destaca é o desenvolvimento de sistemas de liberação controlada de fármacos (SLCs). Os SLCs são nanocarreadores que podem encapsular moléculas 
que apresentam elevada toxicidade e baixa biodisponibilidade e estabilidade físico-química. Dentre os SLC mais utilizados estão os lipossomas.Os lipossomas são nanocarreadores que apresentam uma ou mais bicamadas compostas de fosfolipídios e colesterol em volta de um núcleo aquoso. Essas vesículas podem carrear biomoléculas hidrofílicas e hidrofóbicas, como DNA, RNA, proteínas, vitaminas, fármacos, entre outros, assim proporcionando o aumento do tempo de meia vida e tempo de circulação sistêmica que, por sua vez, possibilita uma redução do número de doses administradas e maior adesão a terapia (Cavalcanti et al., 2015; Bizerra, Silva, 2016).

Ademais, os lipossomas apresentam maior capacidade em otimizar a atividade dos antimicrobianos frente a bactérias resistentes. Eles apresentam uma natureza protetora, pois o fármaco e moléculas encapsuladas ficam protegidas do meio biológico e da ação de moléculas do sistema imunológico do hospedeiro, como interleucinas e proteases do sistema de complemento. Além de melhorar potencialmente a farmacocinética e a farmacodinâmica dos fármacos encapsulados, devido a sua biocompatibilidade e alta biodegradabilidade. Logo, os lipossomas se apresentam como uma alternativa eficaz para encapsulação de fármacos que apresentam baixa biodisponibilidade por liberar o fármaco lentamente e continuamente e/ou certo grau de toxicidade, como é o caso de algumas moléculas de origem vegetal (Liu et al., 2015; Chen et al., 2016).

\section{METODOLOGIA}

Este estudo trata-se de uma revisão integrativa da literatura realizada através de buscas por publicações científicas indexadas nas seguintes bases de dados: PubMed (Publisher Medline), Lilacs (Literatura Latino-Americana e do Caribe em Ciências da Saúde) e SciELO (Scientific Eletronic Library Online). A coleta de dados incluiu artigos publicados entre os anos de 2010 a 2019. Os descritores utilizados foram lipossomas (liposomes), óleos essenciais (essential oils), atividade antimicrobiana (antimicrobial activity) e sistemas de liberação controlada de fármacos (drug delivery systems). Seguindo os critérios de inclusão e exclusão sendo estes, estudos experimentais, disponíveis na íntegra, publicados independente do idioma, nos periódicos indexados foram selecionados 10 artigos. Os artigos selecionados foram lidos, catalogados e analisados dentro da temática sugerida.

\section{RESULTADOS E DISCUSSÕES}

\section{Cravo-da-índia (Syzygium aromaticum)}

O cravo-da-índia, Syzygium aromaticum (SA), pertence à família das Myrtaceae, é 
composto principalmente, por fenilpropanóide, eugenol, $\beta$-cariofileno e o acetato de eugenilo. Essas moléculas são conhecidas por suas aplicações na indústria farmacêutica, pois apresentam, dentre outras atividades, potencial antibacteriano. Entretanto, apresenta limitações consideráveis no que se refere às suas propriedades físico-químicas, pois são quimicamente instáveis na presença de ar, luz, umidade e altas temperaturas (Cui et al., 2015). Dessa forma, muitas estratégias foram utilizadas a fim de melhorar à estabilidade e biodisponibilidade desse OE, entre os quais o uso de SLCs como os lipossomas, é considerado o mais relevante por auxiliar no tratamento de infecções bacterianas. Cui e colaboradores (2015) desenvolveram um estudo para avaliar a atividade antibacteriana do SA encapsulado em lipossomas (SALips), pelo método de contagem de colônias, frente a cepas de Staphylococcus aureus. Nesse estudo, foi demonstrado uma redução de colônias de aproximadamente 99,87\% após 24 horas de tratamento com os SALips.

\section{Alho (Allium sativum L.)}

O alho, Allium sativum L., membro da família Alliaceae, é originalmente da Ásia e amplamente conhecido na culinária de diversos países. Sua atividade antimicrobiana tem sido relatada em vários estudos e, partindo desse conhecimento, Zahibi e colaboradores (2016) propuseram-se a avaliar as características físicoquímicas de $\mathrm{OE}$ de alho encapsulado em lipossomas frente a E. coli O157:H7. A concentração inibitória mínima (CIM) e concentração bactericida mínima (CBM) foram de 0,02\% e 0,03\% para OEs encapsulados em lipossomas, e de $0,03 \%$ e $0,04 \%$ para OE livres. Assim, OE de A. sativum encapsulado em lipossomas demonstrou maior atividade antimicrobiana comparado a sua forma livre.

\section{Árvore do chá (Melaleuca alternifolia)}

Popularmente conhecida como árvore do chá, Melaleuca alternifolia, da família Myrtaceae, produz um óleo com poderosas atividades antibacterianas, antifúngicas, antivirais e antiprotozoárias (Yan e Mingqiao et al., 2016). Para analisar sua atividade antimicrobiana, Yane Mingqiao (2016) encapsularam o óleo da M. alternifolia em lipossomas e avaliaram sua atividade frente a Escherichia coli, Staphylococcus aureus e Candida albicans. Nesse estudo, as CIM do OE foram $0,15 \%-0,3 \%, 0,15 \%-0,3 \%$ e $0,02 \%-0,04 \%$, respectivamente. Os resultados das CBM também foram determinados obtendo valores de 0,15\%-0,3\%, 0,075\%$0,15 \%$ e $0,005 \%-0,01 \%$, respectivamente. Os resultados demonstraram que lipossomas contendo OE obtiveram uma melhora nos aspectos físico-químicos como a solubilidade e permeabilidade, além de que mesmo em baixas concentração de óleo de M. alternifolia 
conseguiu obter uma inibição completa do crescimento microbiano.

\section{Zataria (Zataria multiflora Boiss)}

Zataria, Zataria multiflora Boiss (ZM), é uma erva medicinal aromática distribuída geograficamente nas regiões da Ásia, incluindo Irã, Paquistão e Afeganistão. Representa uma das ervas da família das Lamiaceae com propriedades farmacológicas (Saei-Dehkordi et al., 2010). Levando em consideração as atividades descritas Saei-Dehkordi e Khosravi-Darani (2017) em seus estudos avaliaram a atividade antibacteriana da ZM encapsulada em lipossomas frente a Escherichia coli O157:H7. A enterohemorrágica E. coli sorotipo O157:H7 é o único tipo de E. coli produtora da toxina Shiga, sendo a principal responsável por diarreias. Dessa forma, foram testados e comparados os resultados da ZM livre (ZML) e encapsulada em lipossomas (ZMLips). Em ambos os casos, ZML e ZMLips, a concentração utilizada de ZM foi de $0,04 \%$. A CIM e a CBM para a ZML foi de $0,04 \%$ de $0,08 \%$, respectivamente. Em contrapartida, para a ZMLips, os resultados foram de $0,02 \%$ e $0,04 \%$ respectivamente, demonstrando ser duas vezes menor que a ZML. Dessa forma, o aumento da atividade antimicrobiana após a utilização de ZM encapsulado em lipossomas demonstra que os lipossomas podem ser uma alternativa farmacológica para o tratamento desse sorotipo de $E$. coli.

\section{Sálvia (Salvia triloba)}

Sálvia, Salvia triloba (ST), também é pertencente à família das Lamiaceae e é classificada como Substâncias Geralmente Reconhecidas como Seguras (SGRS) pela Food and Drug Administration (FDA, 2013). Estudos comprovam que seus OEs apresentam propriedades expressivas como antimicrobianos (Risaliti et al., 2019). A fim de explorar a eficácia dos OEs encapsulados em lipossomas frente a Klebsiella pneumoniae, Risaliti e colaboradores (2019) avaliaram em seu estudo a atividade antimicrobiana da ST. Nesse estudo foi percebido que quando submetido apenas a ST livre a inibição da bactéria correspondeu a 12,7 $\pm 0,6 \mathrm{~mm}$, por sua vez, a ST encapsulada em lipossomas apresentou aumento na inibição correspondente a 22,6 \pm 0,6 mm, Assim, a encapsulação de ST em lipossomas pode representar um vetor inovador e completamente biodegradável para a liberação prolongada do OE, preservando ou mesmo e melhorando as propriedades funcionais e biológicas de S. triloba.

\section{Alecrim (Rosmarinus officinalis L.)}

O Alecrim, Rosmarinus officinalis L. (RO), membro da família Lamiaceae, oriundo 
originalmente da região do mediterrâneo ocidental, é bastante utilizado na medicina e na culinária. O seu óleo é composto principalmente de eucaliptol e cânfora e apresenta várias propriedades, dentre elas, a atividade antimicrobiana (Risaliti et al., 2019). Risaliti e colaboradores (2019) encapsularam OE de alecrim em lipossomas e provaram que essa encapsulação apresenta melhor atividade antimicrobiana frente a cepas de Klebsiella pneumoniae, pois nesse estudo, RO livre apresentou halo de inibição de 12,7 \pm 0,6 mm e o RO encapsulado em lipossomas (ROLips) exibiu halo de inibição de 18,5 \pm 0,6 mm.

\section{CONCLUSÕES}

Evidenciou-se que houve um aumento na eficácia dos OEs após sua encapsulação em sistemas de liberação controlada, assim tendo seu potencial antimicrobiano ampliado. Desta forma, o desenvolvimento de pesquisas sobre a avaliação da atividade antibacteriana de OEs encapsulados em lipossomas representa uma grande importância, visto que esses sistemas podem contribuir, no futuro, para a possível diminuição dos casos de infecções.

\section{REFERÊNCIAS}

BIZERRA, A.; SILVA, V. Sistemas de Liberação Controlada: Mecanismos e aplicações. Revista Saúde e Meio Ambiente, v. 3, n. 2, p. 1-12, 2016.

CAVALCANTI, I. M. F. et al. Antimicrobial activity of $\beta$-lapachone encapsulated into liposomes against meticillin-resistant Staphylococcus aureus and Cryptococcus neoformans clinical strains. Journal of Global Antimicrobial Resistance, v. 3, n. 2, p. 103-108, 2015.

COIMBRA, M. et al. Improving solubility and chemical stability of natural compounds for medicinal use by incorporation into liposomes. International journal of pharmaceutics, v. 416, n. 2, p. 433-442, 2011.

CHEN, H. et al. The potential use of novel chitosan-coated deformable liposomes in an ocular drug delivery system. Colloids and surfaces B: biointerfaces, v. 143, p. 455-462, 2016.

CUI, H.; ZHAO, C.; LIN, L. The specific antibacterial activity of liposome-encapsulated Clove oil and its application in tofu. Food Control, vol. 56, p. 128-134, 2015.

ESMAEILI, A. Biological activities of Eremostachys laevigata Bunge. grown in Iran. Pak J Pharm Sci, vol. 25, p. 803-808, 2012.

IBRAHIM, T. A. et al. Chemical composition and antimicrobial activities of essential oils of some coniferous plants cultivated in Egypt. Iranian journal of pharmaceutical research: IJPR, v. 16, n. 1, p. 328, 2017.

KATHIBI, Seyed Amin et al. Encapsulation of Zataria multiflora Bioss. essential oil into nanoliposomes and in vitro antibacterial activity against Escherichia coli O157: H7. Journal 
of Food Processing and Preservation, v. 41, n. 3, p. e12955, 2017.

LIU, J. et al. Liposomes for systematic delivery of vancomycin hydrochloride to decrease nephrotoxicity: Characterization and evaluation. Asian journal of pharmaceutical sciences, v. 10, n. 3, p. 212-222, 2015.

MIRANDA, C. A. S. F et al. Óleos essenciais de folhas de diversas espécies: propriedades antioxidantes e antibacterianas no crescimento espécies patogênicas. Revista Ciência Agronômica, v. 47, n. 1, p. 213-220, 2016.

RAI, M. et al. Synergistic antimicrobial potential of essential oils in combination with nanoparticles: emerging trends and future perspectives. International Journal of Pharmaceutics, v. 519, n. 1-2, p. 67-78, 2017.

RISALITI, L.; et al. Hadjipavlou-Litina, D.; Bilia, A. R. Liposomes loaded with Salvia triloba and Rosmarinus officinalis essential oils: In vitro assessment of antioxidant, antiinflammatory and antibacterial activities. Journal of Drug Delivery Science and Technology, v. 51, p. 493 498, 2019.

SAEI-DEHKORDI, S. S. et al. Chemical composition of essential oils in Zataria multiflora Boiss. from different parts of Iran and their radical scavenging and antimicrobial activity. Food and Chemical Toxicology, v. 48, n. 6, p. 1562-1567, 2010.

SHERRY, M. et al. Essential oils encapsulated in liposomes: a review. Journal of liposome research, v. 23, n. 4, p. 268-275, 2013.

YAN, G.; MINGQIAO, G. Distribution of Melaleuca alternifolia essential oil in liposomes with Tween 80 addition and enhancement of in vitro antimicrobial effect, Journal of Experimental Nanoscience, 11:5, 6345-358, 201 